\title{
Age-related functional changes of total thyroid hormones and glycosaminoglycans in growing calves
}

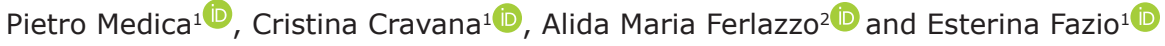 \\ 1. Department of Veterinary Sciences, Unit of Veterinary Physiology, Polo Universitario Annunziata, Messina University, \\ 98168 Messina, Italy; 2. Department of Veterinary Sciences, Unit of Veterinary Biochemistry, Polo Universitario \\ Annunziata, Messina University, 98168 Messina, Italy. \\ Corresponding author: Pietro Medica, e-mail: pmedica@unime.it \\ Co-authors: CC: ccravana@unime.it, AMF: alferl@unime.it, EF: fazio@unime.it \\ Received: 21-11-2019, Accepted: 05-03-2020, Published online: 14-04-2020
}

doi: www.doi.org/10.14202/vetworld.2020.681-686 How to cite this article: Medica P, Cravana C, Ferlazzo AM, Fazio E (2020) Age-related functional changes of total thyroid hormones and glycosaminoglycans in growing calves, Veterinary World, 13(4): 681-686.

\begin{abstract}
Background and Aim: During the physiological growing, thyroid and proteoglycan glycosaminoglycan (GAG) changes dynamically occur, according to genetic and non-genetic factors. The purpose of this research was to compare the effects of early postnatal development (10 days) until 210 days of life on the triiodothyronine $\left(\mathrm{T}_{3}\right)$, thyroxine $\left(\mathrm{T}_{4}\right)$, the relative $\mathrm{T}_{4}: \mathrm{T}_{3}$ ratio, and GAGs profile, and to define the different reference intervals of the calf's development through the various growing phases.
\end{abstract}

Materials and Methods: The effect of growing on total thyroid hormones and GAG profiles was studied from 10 days to 210 days of age in 64 clinically healthy Brown calves, 30 males and 34 females. Blood samples were collected at 10, 20, 30, $60,90,120,150,180$, and 210 days of age.

Results: The results showed a significant effect of a calf's growth on $\mathrm{T}_{3}, \mathrm{~T}_{4}$, and GAG values $(\mathrm{p}<0.0001)$. Significant correlations between $T_{3}$ and $T_{4}$ were observed. Compared to the previous time point, $T_{3}$ showed a significant decrease at 20 days and at 60 days $(\mathrm{p}<0.01)$, while a significant increase was observed at 90 days and 210 days $(\mathrm{p}<0.05)$; $\mathrm{T}_{4}$ showed a significant decrease at 20 days $(p<0.01)$, while significant increases were observed at both 180 days and 210 days $(p<0.05)$; GAGs showed a significant increase at 120 days and 210 days $(\mathrm{p}<0.05)$. Positive and significant correlations between $\mathrm{BW}$ and GAGs in both males $(\mathrm{p}<0.0057)$ and females $(\mathrm{p}<0.0059)$ were observed.

Conclusion: It can be concluded that the highest $\mathrm{T}_{3}$ and $\mathrm{T}_{4}$ concentrations have been associated with the early growing process (10 days), with an increasing trend also at 210 days, it is possible to hypothesize a probable metabolic effect of thyroid function in anabolic and/or catabolic directions during the calves' development. Likewise, it can be reasonably inferred that the highest plasma GAGs at 210 days may be due to their metabolic role during the development of growing calves. Taken together, these findings suggest the potential and relative contribution made by thyroid and GAGs effects on the dynamics of growing calves.

Keywords: calves, glycosaminoglycans, growth, thyroxine, triiodothyronine.

\section{Introduction}

The hypothalamic-pituitary-thyroid (HPT) axis plays a consistent role in the growth and development of fetal and neonatal calves [1,2], according to metabolic and non-metabolic mechanisms [3-5]. Indeed, thyroid hormones play a crucial role in successful implantation and during the early stages of embryo development [6,7], suggesting a local action of thyroid hormones and thyroid-stimulating hormone (TSH) on both the endometrium and the embryo $[8,9]$. Several reports indicated that the fetal number also affected the circulating thyroid hormones during pregnancy of ewes [10-12].

\footnotetext{
Copyright: Medica, et al. Open Access. This article is distributed under the terms of the Creative Commons Attribution 4.0 Internationa License (http://creativecommons.org/licenses/by/4.0/), which permits unrestricted use, distribution, and reproduction in any medium, provided you give appropriate credit to the original author(s) and the source, provide a link to the Creative Commons license, and indicate if changes were made. The Creative Commons Public Domain Dedication waiver (http://creativecommons.org/ publicdomain/zero/1.0/) applies to the data made available in this article, unless otherwise stated.
}

Fetal thyroid function is under a strong maternal thyroid axis's influence, on the basis of placental permeability for iodine, improving fetal thyroid hormone synthesis $[13,14]$. Nevertheless, there is no evidence about thyroid hormones transfer through the ruminants' placenta [2]. During the physiological development, thyroid changes dynamically occur, according to genetic and non-genetic factors, nutritional intake [15], environmental stimuli [16], and deiodinases' expression [2]. High fetal thyroid hormones' concentration after birth in 1 day old neonatal calves were observed, and a significant decrease along the next several days was also recorded, providing sufficient amounts of thyroid hormones for early postnatal development [17]. An interplay between fetal thyroid function and skeletal muscle development, in both sheep [4,18] and cattle [19], and the initiation of neonatal thermogenesis [20], was reported.

Glycosaminoglycans (GAGs) are heteropolysaccharides, widely distributed in mammals' tissues, which display varied stereochemistry, chain lengths, and patterns of sulfatation. GAG-protein interactions 
participate in neuronal development, angiogenesis, and other functions such as immune responses [21]. Recently, the implications for proteoglycan signaling, and the identification of novel binding sites in receptor protein-tyrosine phosphatase in modulating neural development and regeneration, were also suggested [22]. Fetal calf serum supported high levels of $[3 \mathrm{H}]$ glucosamine incorporation into hyaluronic acid, in a dose-dependent manner, while newborn calves and calf sera supported much lower levels of incorporation [23]. It is also worth noting that proteoglycans in endochondral ossification were observed and that they appear to persist unaltered in the calcified cartilage core of the trabeculae, until the primary spongiosa is replaced by the secondary spongiosa [24]. There are age and site related differences in the extent of proteoglycans isolated aggregates in cephalic, epiphyseal, and articular cartilages, in growing sheep [25] and deer (Cervus Nippon) [26].

The hypothesis of the work was the supposed existence of functional differences in the same individuals during the $1^{\text {st }} 210$ days of life, reflecting the metabolic shift from the onset of growth and the dynamic development of neonatal calves. The primary objective of the present research was to compare the effect of early postnatal development (10 days) until 210 days of life on the total thyroid hormones, the relative $T_{4}: T_{3}$ ratios, and GAGs profile. The secondary one was to establish whether changes in the ranges of circulating compounds were suitable to define different reference intervals of the calf throughout the growing phases.

The current study therefore underlines the importance of these parameters, with consistent metabolic effects, throughout the growing phases, coupled with information on their comparative involvement in interpreting physiological or clinical conditions.

\section{Materials and Methods}

\section{Ethical approval}

All methods and procedures used in this study were in compliance with the guidelines of Italian law (D.L. 04/3/2014 n. 26) and EU directive (2010/63/ EU) on the protection of animals used for scientific purposes.

\section{Animals}

Sixty-four clinically healthy Brown calves, 30 males and 34 females, born in early November and kept out with dams until weaning, were investigated during the $1^{\text {st }} 210$ days of age, from 10 to 210 days. The calves were fed on their dam's milk until weaning and all calves were weaned at 6 months.

During the experimental period, individual live body weights (BW) were recorded monthly using a large animal scale.

\section{Samples collection}

Calves were sampled on a farm located

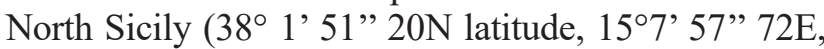

longitude) between March and September, 2018. Blood samples were taken from the jugular vein at 10, 20, 30, $60,90,120,150,180$, and 210 days of life, respectively. All samples were taken between 07:00 and 09:00 a.m. to minimize the effect of circadian rhythm on hormonal measurements. During blood collection, the animals received minimum handling, and minimal physical restriction was involved to reduce handling stress. Blood samples were collected in quiet conditions by the same veterinarian, by jugular venipuncture and drawn into a plain vacutainer tube for serum (Venoject, Terumo $^{\circledR}$; Belgium). The blood samples were centrifuged for $15 \mathrm{~min}$ at $1500 \times \mathrm{g}$, and serum was separated. The serum samples were stored frozen in polystyrene tubes at $-20^{\circ} \mathrm{C}$ and assayed for thyroxine and triiodothyronine. For plasma preparation, blood was collected into tubes containing EDTA and then separated by centrifugation at $1500 \times g$. The samples were either immediately processed for GAGs separation, or transferred to plastic vials and stored at $-20^{\circ} \mathrm{C}$ until analysis.

\section{Sample analysis}

Thyroid hormone assays were analyzed in duplicate using a commercially available immunoenzymatic kit and carried out according to the manufacturer's instructions (SEAC-RADIM; Pomezia, Rome). Limits of detection were $0.24 \mathrm{nmol} / \mathrm{L}$ for $\mathrm{T}_{3}$ and $5.79 \mathrm{nmol} / \mathrm{L}$ for $\mathrm{T}_{4}$. Intra-assay and inter-assay coefficients of variation were $7.3 \%$ and $11.4 \%$ for $\mathrm{T}_{3}, 2.3 \%$ and $5.7 \%$ for $\mathrm{T}_{4}$, respectively, on the basis of measurements, in three different samples. The commercial kits were validated for total iodothyronines by establishing that dilutions of ovine serum resulted in curves identical to those obtained with the human standards supplied with the assay kits.

Isolation of GAGs from plasma used reagents of analytical grade (Merck, Darmstad, Germany; Fluka, Buchs, Switzerland; Sigma, St. Louis, MO, U.S.A.). The ion-exchanger ecteola-cellulose was from Fluka and standard sugars from Sigma. The GAG isolation from plasma preparations was performed as described in detail elsewhere [27]. A known amount (1-5 ml) of plasma, diluted to double volume with water, was held in alkaline conditions $(0.05 \mathrm{M} \mathrm{NaOH})$ at $40^{\circ} \mathrm{C}$ for $16 \mathrm{~h}$ to cleave covalent O-linkages between protein and carbohydrate and to release GAG chains from proteoglycans or peptidoglycans [28]. The sample, cooled to room temperature, was neutralized to $\mathrm{pH}$ 6-6.5 by adding $1 \mathrm{M} \mathrm{HCl}$ solution. GAG chains were then isolated by filtering the neutralized samples through columns $(0.7 \times 4 \mathrm{~cm}$ columns were used for $2 \mathrm{ml} \mathrm{sam}-$ ples) of the weak anion exchanger Ecteola-cellulose (Fluka), in chloride form. The resin was washed with $50 \mathrm{ml}$ of $0.15 \mathrm{M} \mathrm{NaCl}$ solution and then GAGs were eluted by $4 \mathrm{ml}$ of $2 \mathrm{M} \mathrm{NaCl}$ solution and quantified in terms of hexuronic acid.

\section{Statistical analysis}

Data are presented as mean \pm standard deviation (S.D.). To analyze differences for previous time points, one-way analysis of variance for repeated 
measures (one-way RM ANOVA) was applied. When the $\mathrm{F}$ value was significant, differences between individual means were assessed with a post hoc test (Bonferroni). Significant differences between males and females were established using Student's unpaired t-test. The level of significance was set at $\mathrm{p}<0.05$. All calculations were performed using the GraphPad Prism version 7.0 for Windows (GraphPad Software Inc., San Diego, CA, USA). The correlations between BW measurements, age, thyroid hormones, and GAGs were calculated using the Pearson's linear regression, r. The correlations between age, thyroid hormones, and GAGs were also evaluated.

\section{Results}

\section{Growing effect}

The growth in $\mathrm{BW}$, total iodothyronine, $\mathrm{T}_{4} / \mathrm{T}_{3}$ ratio, and GAG concentrations in calves from 10 to 210 days of age is, respectively, shown in Table- 1 and Figures-1-4. The effect of growth was observed for $\mathrm{T}_{3}$ $(\mathrm{F}=1.25 ; \mathrm{p}<0.0001), \mathrm{T}_{4}(\mathrm{~F}=1.46 ; \mathrm{p}<0.0001)$, and $\mathrm{GAG}$ $(\mathrm{F}=17.24 ; \mathrm{p}<0.0001)$ values.

Serum $\mathrm{T}_{3}$ concentrations averaged, respectively, 3.96 and $1.90 \mathrm{nmol} / \mathrm{L}$ at 10 and 60 days, showing a twophase trend, with a decrease from 20 days to 60 days and a trend to increase from 90 days to 120 days. Specifically, compared to the previous time point, $\mathrm{T}_{3}$ showed lower concentrations at 20 days $(\mathrm{p}<0.01)$ and 60 days $(\mathrm{p}<0.01)$ of age, and higher concentrations at 90 days and 210 days $(\mathrm{p}<0.05)$.

Table-1: Growth in body weight $(M \pm S D)$ in growing calves from 10 to 210 days of age.

\begin{tabular}{lcc}
\hline Age (days) & \multicolumn{2}{c}{ BW (kg) } \\
\cline { 2 - 3 } & Males (30) & Females (34) \\
\hline 10 & $10.09 \pm 2.23$ & $8.50 \pm 1.14$ \\
20 & $8.02 \pm 1.44$ & $7.53 \pm 1.17$ \\
30 & $14.22 \pm 3.53$ & $13.64 \pm 2.90$ \\
60 & $35.44 \pm 3.62$ & $34.33 \pm 3.39$ \\
90 & $43.89 \pm 1.88$ & $44.67 \pm 0.97$ \\
120 & $17.80 \pm 1.38$ & $17.13 \pm 1.45$ \\
150 & $40.81 \pm 2.38$ & $38.93 \pm 2.45$ \\
180 & $17.41 \pm 1.62$ & $18.33 \pm 1.39$ \\
210 & $128.19 \pm 35.88$ & $158.17 \pm 33.47$ \\
\hline
\end{tabular}

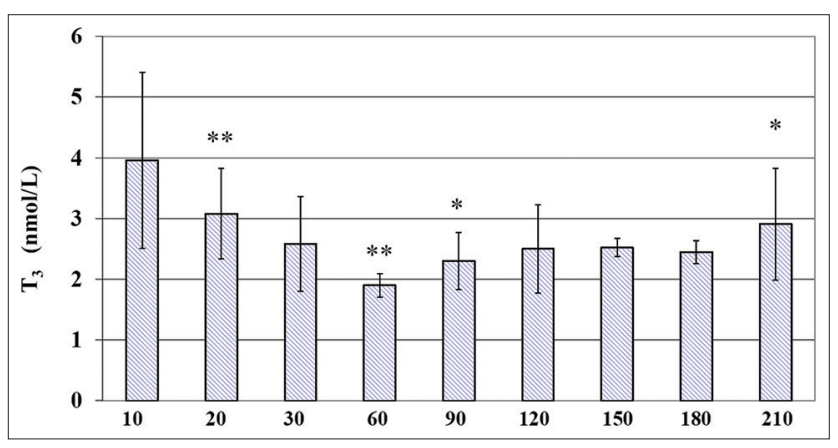

Figure-1: Circulating total triiodothyronine (T3) concentrations $(M \pm S D)$ in growing calves over a period of 210 days. *Indicates significant $(* p<0.05 ; * * p<0.01)$ differences in average hormone concentrations versus previous time point.
Serum $\mathrm{T}_{4}$ concentrations averaged, respectively, 160.23 and $86.74 \mathrm{nmol} / \mathrm{L}$ at 10 days and at 120 days, showing a three-phase trend, with a decrease at 20 days, a plateau from 30 days to 150 days, and an increase at both 180 days and 210 days. Specifically, compared to the previous time point, $\mathrm{T}_{4}$ showed lower concentrations at 20 days $(\mathrm{p}<0.01)$ and significant increases at both 180 days and 210 days $(\mathrm{p}<0.05)$.

Significant correlations between $\mathrm{T}_{3}$ and $\mathrm{T}_{4}$ along 210 days of age $(r=0.71 ; \mathrm{p}=0.029)$ were observed.

Plasma GAGs concentrations averaged, respectively, 30.60 and $10.21 \mathrm{ng} / \mathrm{L}$ at 210 and 60 days, showing a two-phase trend, with the lower concentrations from 10 days to 90 days, in comparison with values observed from 120 days to 210 days. Specifically, compared to the previous time point, GAGs showed a significant increase at 120 days and 210 days $(p<0.05)$.

The average values of $\mathrm{T}_{4}: \mathrm{T}_{3}$ ratio in growing calves were 54.86:1 and 34.42:1 at 60 days and 20 days, respectively, showing a variable trend, with

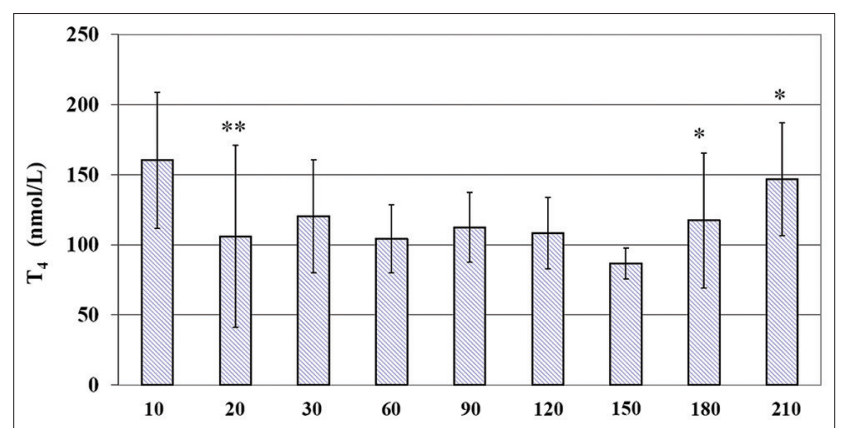

Figure-2: Circulating total thyroxine $\left(T_{4}\right)$ concentrations $(M \pm S D)$ in growing calves over a period of 210 days. $*$ indicates significant $(* p<0.05 ; * * p<0.01)$ differences in average hormone concentrations vs previous time point.

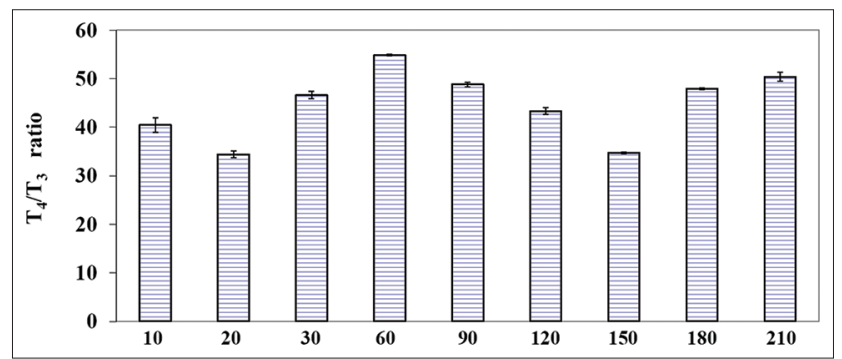

Figure-3: $T_{4} / T_{3}$ ratio in growing calves over a period of 210 days.

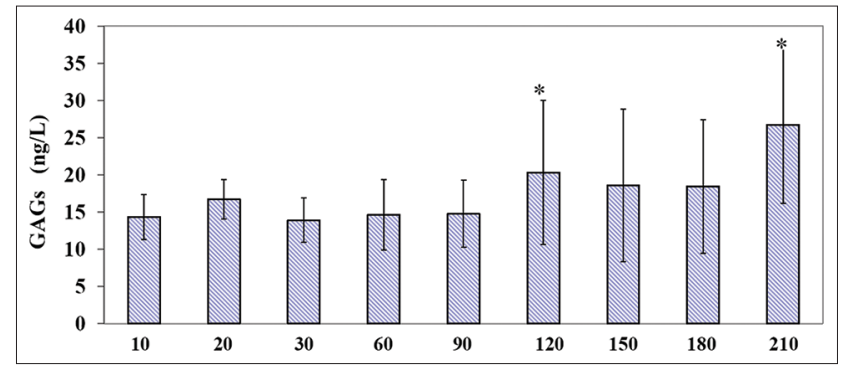

Figure-4: Circulating glycosaminoglycan concentrations $(M \pm S D)$ in growing calves over a period of 210 days. *indicates significant $(* p<0.05)$ differences in average hormone concentrations versus previous time point. 
a decrease at 20 days, a plateau from 30 days to 120 days, a decrease at 150 days and an increase at both 180 days and 210 days.

\section{Gender effect}

No gender effects $(p>0.05)$ were shown for $\mathrm{T}_{3}, \mathrm{~T}_{4}$, and GAG concentrations. Males and females showed the typical trend of total iodothyronines and GAGs observed in total calves. No significant differences were observed between males and females for total thyroid hormones and GAG concentrations.

In addition, there were positive correlations between BW and GAGs in both males $(r=0.83$; $\mathrm{p}<0.0057)$ and females $(\mathrm{r}=0.83 ; \mathrm{p}<0.0059)$.

\section{Discussion}

Reliable reference values for thyroid hormone concentrations in blood of clinically normal animals have been established by many researches, but limited data are available for GAGs [27]. In fact, many physiological factors that affect thyroid function and GAG metabolism may lead to misinterpretation of average results when values for individual specimen are compared with reference values. Comparisons of total iodothyronine and GAG concentrations with published data for calves under 3 months [29] and cattle [27] did not reveal any large discrepancies. However, slight variation might be ascribed to differences in sample collection and processing or laboratory analyses; some differences may be also explained by age, nutritional, managing, or environmental factors.

The obtained data confirm the presence of high concentrations of circulating $\mathrm{T}_{3}$ and $\mathrm{T}_{4}$ hormones in calves, previously reported in the calves and heifers of Bos frontalis [30,31], and during the first 6 months of life [32]. Furthermore, the highest concentration of $\mathrm{T}_{3}$ observed at 10 days in calves and then decreasing with advancing age is in accordance with Garg et al. [30] and Lalsangpuii et al. [31] showing a probably adaptive mechanism to overcome the stressful period compared to other age periods; it is therefore reasonable that a decreased $\mathrm{T}_{3}$ metabolic clearance occurred, due to low capability of its degrading enzymatic system observed in heifer [31] and/or to lower metabolic load [32].

The steady high patterns of $\mathrm{T}_{3}$ and $\mathrm{T}_{4}$ at the $1^{\text {st }} 10$ days and also at 210 days of age, of growing calves could be associated with a concomitant increased synthesis of $\mathrm{T}_{4}$ and with the higher monodeiodination rate of $\mathrm{T}_{4}$ to $\mathrm{T}_{3}$. Besides, the very high plasma GAG's values at 210 days of life appear to have a consistent and concomitant metabolic role involved in the development and differentiation of young growing calves.

Moreover, serum $\mathrm{T}_{3}$ and $\mathrm{T}_{4}$ concentrations were relatively stable in growing calves along 120-180 days and 30-150 days of life, respectively, according to the shift in energy consumption. In fact, circulating $\mathrm{T}_{4}$ concentrations were found to be an indicator of energy balance, BW gain, and protein deposition, as reported by Ellenberger et al. [33] and Hayden et al. [34] in steers.

The key finding in the present study was the time courses of $T_{4}$ and $T_{3}$ changes that were different during the growing period, with a positive correlation between total iodothyronines in the growing calves, confirming this relationship previously described in both buffaloes [3] and goats at different ages [35]. On this basis, $\mathrm{T}_{3}$ and $\mathrm{T}_{4}$ concentrations appear to be much more susceptible to variations attributable to many exogenous influences, commonly associated with growing calves, than to GAGs trend.

One possibility is that the rise of $\mathrm{T}_{3}$ at 90 days and 210 days and of $T_{4}$ at 180 days and 210 days, respectively, led to metabolic effects not measured in this research. These data suggest that both $\mathrm{T}_{3}$ and $\mathrm{T}_{4}$ may contribute to homeostasis during the anabolic processes, and the endocrine changes may, therefore, be the physiological responses to growing itself.

The present data do not completely elucidate the significance of changes in circulating total iodothyronines in calves. However, thyroid changes may be both the cause and the consequence of growth programming.

Changes in plasma GAGs generally followed those for $\mathrm{T}_{3}$. However, the changes observed during the $1^{\text {st }} 60$ days of age were modest and inconsistent.

Total iodothyronines appear to act synergically with GAGs to hasten development especially of the musculoskeletal and nervous system and to improve postnatal adaptation including extremely high thermogenic capacity [36].

The existence of positive correlations between $\mathrm{T}_{3}$ and $\mathrm{T}_{4}$ concentrations confirms that $\mathrm{T}_{3}$ is the most metabolically active iodothyronine [37], especially during normal growth and development, showing a pivotal role in regulation of growth processes and energy metabolism $[3,38]$. Hence, serum $\mathrm{T}_{4}$ concentrations represent a result of the balance between thyroidal secretion and peripheral metabolism that increases according to the growing period [39].

GAGs profile showed a superimposed effect on growing calves, according to different age, playing a crucial key role in physiological development of bone, joint and tooth and signaling events, with a significant relevance to therapeutic options, as showed by the positive correlation between GAGs and body weight.

\section{Conclusion}

It can be concluded that the highest $\mathrm{T}_{3}$ and $\mathrm{T}_{4}$ concentrations have been associated with the early growing process (10 days), with an increasing trend also at 210 days, it is possible to hypothesize a probable metabolic effect of thyroid function in anabolic and/or catabolic directions during the calves' development. Likewise, it can be reasonably inferred that the highest plasma GAGs at 210 days may be due to their metabolic role during the development of growing calves. Taken together, these findings suggest the 
potential and relative contribution made by thyroid and GAGs effects on the dynamics of growing calves.

\section{Authors' Contributions}

$\mathrm{EF}$ and PM conceived the study designed. AMF performed the experiment. $\mathrm{PM}$ and $\mathrm{CC}$ analyzed the data. EF and PM drafted and revised the manuscript. All authors read and approved the final manuscript.

\section{Acknowledgments}

We gratefully acknowledge the help of farm staff, veterinarian and technicians during the sample collection, preparation, and analyses. This research did not receive any specific grant from funding agencies in the public, commercial, or not-for-profit sectors.

\section{Competing Interests}

The authors declare that they have no competing interests.

\section{Publisher's Note}

Veterinary World remains neutral with regard to jurisdictional claims in published institutional affiliation.

\section{References}

1. Hillman, N.H., Kallapur, S.G. and Jobe, A.H. (2012) Physiology of transition from intrauterine to extrauterine life. Clin. Perinatol., 39(4): 769-783.

2. Kirovski, D., Dodovski, P., Savić, D., Vujanac, I., Prodanović, R., Mirilović, M., Sladojević, Ž. and Djordjević, A. (2016) Placental iodothyronine deiodinases expression in pregnant cows exposed to propylthiouracil (PTU) and thyroid axis activity of their calves. Acta Vet. Beograd, 66(1): 61-75.

3. Ingole, S.D., Deshmukh, B.T., Nagvekar, A.S. and Bharucha, S.V. (2012) Serum profile of thyroid hormones from birth to puberty in buffalo calves and heifers. $J$. Buffalo Sci., 1(1): 39-49.

4. Forhead, A.J. and Fowden, A.L. (2014) Thyroid hormones in fetal growth and prepartum maturation. J. Endocrinol., 221(3): R87-R103.

5. Moog, N.K., Entringer, S., Heim, C., Wadhwa, P.D., Kathmann, N. and Buss, C. (2017) Influence of maternal thyroid hormones during gestation on fetal brain development. Neuroscience, 342: 68-100.

6. Colicchia, M., Campagnolo, L., Baldini, E., Ulisse, S., Valensise, H. and Moretti, C. (2014) Molecular basis of thyrotropin and thyroid hormone action during implantation and early development. Hum. Reprod. Update, 20(6): 884-904.

7. Piccirilli, D., Baldini, E., Massimiani, M., Camaioni, A., Salustri, A., Bernardini, R., Centanni, M., Ulisse, S., Moretti, C. and Campagnolo, L. (2018) Thyroid hormone regulates protease expression and activation of Notch signaling in implantation and embryo development. $J$. Endocrinol., 236(1): 1-12.

8. Evers, A.S. (2012) Paracrine interactions of thyroid hormones and thyroid stimulating hormone in the female reproductive tract have an impact on female fertility. Front. Endocrinol. Lausanne, 3: 50.

9. Salleh, N., Sayem, A.S.M., Giribabu, N. and Khaing, S.L. (2019) Expression of proteins related to thyroid hormone function in the uterus is down-regulated at the day of implantation in hypothyroid pregnant rats. Cell Biol. Int., 43(5): 486-494

10. Coledel, M.M., Martins, E., Martins, M.V.D. and
Júnior, A.P.M. (2010) Serum concentration of thyroid hormones in crioula lanada serrana ewes in gestation and lactation. Arch. Zootec., 59(228): 509-517.

11. Abdollahi, E., Kohran, H. and Shahir, M.H. (2013) Plasma concentrations of essential trace microminerals and thyroid hormones during single or twin pregnancies in fat-tailed ewes. Small Rumin. Res., 113(2-3): 360-364.

12. Opazo, M.C., Haensgen, H., Bohmwald, K., Venegas, L.F., Boudin, H., Elorza, A.A., Simon, F., Fardella, C., Bueno, S.M., Kalergis, A.M. and Riedel, C.A. (2017) Imprinting of maternal thyroid hormones in the offspring. Int. Rev. Immunol., 36(4): 240-255.

13. Yarrington, C. and Pearce, E.N. (2011) Iodine and pregnancy. J. Thyroid Res., 2011: 934104.

14. Munoz, J.L. (2019) Fetal thyroid disorders: Pathophysiology, diagnosis and therapeutic approaches. J. Gynecol. Obstet. Hum. Reprod., 48(4): 231-233.

15. Micke, G.C., Sullivan, T.M., Kennaway, D.J., HernandezMedrano, J. and Perry, V.E.A. (2015) Maternal endocrine adaptation throughout pregnancy to nutrient manipulation: Consequences for sexually dimorphic programming of thyroid hormones and development of their progeny. Theriogenology, 83(4): 604-615.

16. Todini, L. (2007) Thyroid hormones in small ruminants: Effectsof endogenous, environmental and nutritional factors. Animal, 1(7): 997-1008.

17. Kirovski, D. (2015) Endocrine and metabolic adaptation of calves to extrauterine life. Acta Vet. Beograd, 65(3): 297-318

18. Bloise. F.F., Cordeiro, A. and Ortiga-Carvalho, T.M. (2018) Role of thyroid hormone in skeletal muscle physiology. $J$. Endocrinol., 236(1): R57-R68.

19. Cassar-Malek, I., Picard, B., Kahl, S. and Hocquette, J.F. (2007) Relationships between thyroid status, tissue oxidative metabolism, and muscle differentiation in bovine fetuses. Domest. Anim. Endocrinol., 33(1): 91-106.

20. Roland, L., Drillich, M., Klein-Jöbstl, D. and Iwersen, M. (2016) Invited review: Influence of climatic conditions on the development, performance, and health of calves. $J$. Dairy Sci., 99(4): 2438-2452.

21. Griffith, A.R., Rogers, C.J., Miller, G.M., Abrol, R., HsiehWilson, L.C. and Goddard, W.A. (2017) Predicting glycosaminoglycan surface protein interactions and implications for studying axonal growth. Proc. Natl. Acad. U.S.A, 114(52): 13697-13702.

22. Katagiri, Y., Morgan, A.A., Yu, P., Bangayan, N.J., Junka, R. and Geller, H.M. (2018) Identification of novel binding sites for heparin in receptor protein. Tyrosine phosphatase (RPTP): Implications for proteoglycan signaling. J. Biol. Chem., 293(29): 11639-11647.

23. Huey, G., Moin, A. and Stem, R., (1990) Levels of [3H]glucosamine incorporation into hyaluronic acid by fibroblasts is modulated by culture conditions. Matrix, 10(2): 75-83.

24. Poole, A.R., Pidoux, I. and Rosenberg, L. (1982) Role of proteoglycans in endochondral ossification: Immunofluorescent localization of link protein and proteoglycan monomer in bovine fetal epiphyseal growth plate. $J$. Cell Biol., 92(2): 249-260.

25. Bollen, A.M., Carlson, D.S. and Dziewiatkowski, D.D. (1990) Aggregation of proteoglycans in cephalic, epiphyseal and articular cartilages in growing sheep. Connect. Tissue Res., 24(2): 121-127.

26. Takeda-Okuda, N., Mizumoto, S., Zhang, Z., Kim, S.K., Lee, C.H., Jeon, B.T., Hosaka, Y.Z., Kadomatsu, K., Yamada, S. and Tamura, J.I. (2019) Compositional analysis of the glycosaminoglycan family in velvet antlers of Sika deer (Cervus nippon) at different growing stages. Glycoconj. J., 36(2): 127-139.

27. Ferlazzo, A.M., Vinci, R., Panzera, M., Ferlazzo, A. and Calatroni, A. (1991) Glycosaminoglycan concentrations in horse plasma and serum. Differences with other animal species and identification of affecting factors. Comp. Biochem. 
Physiol. B, 100(4): 745-751.

28. Muraca, U., Vinci, R., Ferlazzo, A.M., Muraca, G. and Calatroni, A. (1992) Factors affecting glycosaminoglycan concentration in normal human plasma. Ital. J. Biochem., 41(3):159-169.

29. Larsson, B., Travén, M., Hulten, C., Segerstad, C. Belak, K. and Alenius, S. (1995) Serum concentrations of thyroid hormones in calves with a transient or persistent infection with bovine viral diarrhoea virus. Res. Vet. Sci., 58(2): 186-189.

30. Garg, S.L., Sharma, S., Rose, M.K. and Agarwal, V.K. (2002) Age associated variations in peripheral concentration of certain hormones of female buffalo calves from birth to puberty. Indian J. Anim. Sci., 72(7): 579-581.

31. Lalsangpuii, K., Ali, M.A., Devi, L.I., Behera, P. and Ralte, L. (2015) Effect of age and season on the thyroid hormone activity of Mizoram strain female Mithun (Bos frontalis). Vet. World, 8(12): 1375-1378.

32. Iveta, P., Seidel, H., Nagy, O., Tóthová, C. and Kováč, G. (2011) Concentrations of thyroid hormones in various age categories of ruminants and swine. Acta Vet. Beograd, 61(56): 489-503.

33. Ellenberger, M.A., Johnson, D.E., Carstens, G.E., Hossner, K.L., Holland, M.D., Nett, T.M. and Nockels, C.F.
(1989) Endocrine and metabolic changes during altered growth rates in beef cattle. J. Anim. Sci., 67(6); 1446-1454.

34. Hayden, J.M., Williams, J.E. and Collier, R.J. (1993) Plasma growth hormone, insulin-like growth factor, insulin, and thyroid hormone association with body protein and fat accretion in steers undergoing compensatory gain after dietary energy restriction. J. Anim. Sci., 71(12): 3327-3338.

35. Bhooshan, N., Kumar, P., Singh, S.K. and Yadav, M.C. (2010) Status of thyroid hormones in blood plasma of goats at different ages and their correlation with other biochemical parameters. Indian J. Anim. Sci., 80(7): 634-637.

36. Saber, A.P.R., Jalali, M.T., Mohjeri, D., Akhoole, A.A., Teymourluei, H.Z.N., Nouri, M. and Garachorlo, S. (2009) The effect of ambient temperatures on thyroid hormone concentration and histopathological changes of thyroid gland in cattle in Tabriz, Iran. Asian J. Anim. Vet. Adv., 4(1): 28-33.

37. Tata, J.R. (2011) Looking for the mechanism of action of thyroid hormone. J. Thyroid Res., 2011: 730630.

38. Yavuz, S., del Prado, S.S.N. and Celi, F.S. (2019) Thyroid hormone action and energy expenditure. J. Endocr. Soc., 3(7): $1345-1356$

39. Kelly, G. (2000) Peripheral metabolism of thyroid hormones: A review. Altern. Med. Rev., 5(4): 306-333. 